\title{
Psychometric properties of the Caregiver Preparedness Scale in caregivers of stroke survivors
}

\author{
Gianluca Pucciarelli, RN, MSN ${ }^{\mathrm{a}}$, Serenella Savini, RN, PhD ${ }^{\mathrm{a}}$, \\ Eeeseung Byun, PhD, RN, ACNP-BC ${ }^{\mathrm{b}}$, Silvio Simeone, RN, MSN ${ }^{\mathrm{a}}$, \\ Claudio Barbaranelli, $\mathrm{PhD}^{\mathrm{c}}$, Raúl Juárez Vela, RN, PhD ${ }^{\mathrm{d}}$, Rosaria Alvaro, RN, MSN ${ }^{\mathrm{a}}$, \\ Ercole Vellone, RN, MSN ${ }^{\mathrm{a}, *}$ \\ a Department of Biomedicine and Prevention, University of Rome "Tor Vergata", Rome, Italy \\ ${ }^{\mathrm{b}}$ Department of Family Health Care Nursing, University of California San Francisco School of Nursing, San Francisco, CA, USA \\ ${ }^{\mathrm{c}}$ Department of Psychology, Sapienza University, Rome, Italy \\ ${ }^{\mathrm{d}}$ Faculty of Health Sciences, University San Jorge, Zaragoza, Spain
}

\section{A R T I C L E I N F O}

\section{Article history:}

Received 12 June 2014

Received in revised form

19 August 2014

Accepted 19 August 2014

Available online $\mathrm{xxx}$

\section{Keywords:}

Caregivers

Preparedness

Psychometrics

Stroke

Validity

Reliability

\begin{abstract}
A B S T R A C T
Objective: To evaluate the psychometric characteristics of the Caregiver Preparedness Scale (CPS) in caregivers of stroke survivors.

Background: Caregiver preparedness can have an important impact on both the caregiver and the stroke survivor. The validity and reliability of the CPS has not been tested for the stroke-caregiver population. Methods: We used a cross-sectional design to study a sample of 156 caregivers of stroke survivors. Construct validity of the CPS was evaluated by confirmatory factor analysis (CFA). Internal consistency and test-retest reliability were also evaluated.

Results: Caregivers were, on average, 54 year old (SD = 13.2) and most were women (64.7\%). CFA supported the unidimensionality of the scale (comparative fit index $=0.98$ ). Reliability was also supported: item-reliability index and item-total correlations above 0.30 ; composite reliability index $=0.93$; Cronbach's alpha $=0.94$; factor score determinacy $=0.97$; and test-retest reliability $=0.92$.

Conclusion: The CPS is valid and reliable in caregivers of stroke survivors. Scores on this scale may assist health-care providers in identifying caregivers with less preparedness to provide specific interventions.
\end{abstract}

(c) 2014 Elsevier Inc. All rights reserved.

\section{Introduction}

In the industrialized world, $25 \%$ of people aged 65-69 years and $50 \%$ of people aged $80-84$ years are affected by chronic health conditions. ${ }^{1}$ The majority of these older adults are cared for by informal caregivers such as family or friends in the community. ${ }^{2}$ In the United States, approximately 43.5 million informal caregivers provide care to older adults with chronic disease. ${ }^{3}$ In Europe, 125

Abbreviations: ADL, activities of daily living; CFA, confirmatory factor analysis; CFI, Comparative Fit Index; CPS, Caregiver Preparedness Scale; ICC, Intraclass Correlation Coefficient; RMSEA, Root Mean Square Error of Approximation; SRMR, Standardized Root Mean Square Residual; TLI, Tucker and Lewis's Incremental Index.

* Corresponding author. Department of Biomedicine and Prevention, Via Montpellier, 1, University of Rome “Tor Vergata”, 00133 Rome, Italy. Tel.: +3906 72596802; fax: +3906 72596961.

E-mail address: ercole.vellone@uniroma2.it (E. Vellone). million people serve as informal caregivers for people with functional limitations in performing activities of daily living (ADL). ${ }^{4,5}$ In Italy, where this study was conducted, more than 500,000 older adults are cared for by informal caregivers in their home. The majority of older adults suffer from chronic and complex conditions (e.g., hypertension, heart disease, diabetes, stroke, depression, and cancer) and require assistance in daily care from their family members. ${ }^{6}$ The number of caregivers is expected to increase in the near future because the population is rapidly aging. ${ }^{7}$

Caregivers are important resources for health-care systems and society. ${ }^{8,9}$ In the United States, economic value of caregiving was estimated to be $\$ 350$ billion in $2006 .^{9}$ Several studies, however, found that caregivers may not be well prepared to provide appropriate care, such as monitoring symptoms, coordinating care, or recognizing and intervening in case of complications. ${ }^{2,10,11}$ Less prepared caregivers worry about care, ${ }^{12}$ feel burden, strain and tension, ${ }^{13}$ and experience mood disturbances. ${ }^{14}$ In addition, caregivers with less caregiving preparedness have poorer health than 
those with better caregiving preparedness. ${ }^{15}$ In contrast, wellprepared caregivers with appropriate skills and knowledge in caring for their relatives are less depressed and anxious and have higher levels of hope. ${ }^{16}$

The majority of strokes, especially ischemic strokes, occur among older adults. The stroke incidence rate is estimated to be between 7.5 and 10.1 per 1000 persons. ${ }^{17,18}$ Stroke survivors are generally discharged home in a short period of time and require assistance in performing ADL, even after rehabilitation. ${ }^{19}$ Caregivers of stroke survivors play a pivotal role in assisting in the physical, cognitive and emotional needs of stroke survivors ${ }^{20}$; however, they often feel unprepared for their new caregiver role. ${ }^{21,22}$ These issues can cause increased errors in care, duplication of services, and inappropriate or absent treatment for stroke survivors, and even increased risk for patients' readmission to hospital. ${ }^{23}$ Several studies demonstrated that well-prepared caregivers can significantly influence stroke survivors' recovery and quality of life. ${ }^{16,24}$ Thus, it is important for health-care providers to evaluate preparedness of informal caregivers, especially when the caregiver is beginning the new role as caregiver.

To measure preparedness for caregiving, Archbold et $\mathrm{al}^{25}$ developed the Caregiver Preparedness Scale (CPS). Caregiver preparedness was defined as perceived preparation of caregivers to care for the physical and emotional needs of the patient. The definition of caregiver preparedness includes the caregiver's perception of their ability to arrange for services for the care recipient and handle emergent situations. Although the CPS was not developed based on a theory of caregiver preparedness, it has been used to measure caregiver preparedness in several caregiver populations such as caregivers for patients with cancer, ${ }^{10,26}$ life-threatening illness, ${ }^{27,28}$ coronary artery disease, ${ }^{29}$ and Parkinson's disease. ${ }^{12}$

Despite wide use of the CPS, to our knowledge only three studies have tested the factorial structure and reliability of the scale. The first study was conducted in the United States, ${ }^{25}$ where the CPS was developed, with a sample of caregivers of older adults who required assistance to take medications or for ADL. The factorial structure of the CPS was tested with exploratory factor analysis, which generated one factor explaining 50\% of CPS variance. Internal-consistency reliability of the CPS, tested with Cronbach's alpha, was 0.72 at 6 weeks and 0.71 at 9 months after hospital discharge. When the Cronbach's alpha is $\geq 0.70$ the research instrument is considered reliable. ${ }^{30}$

Researchers also tested the CPS for validity and reliability on caregivers of palliative care patients in two studies conducted in Australia and Sweden. ${ }^{26,27}$ In the Australian study, they evaluated the factorial validity of the CPS with Principal Components Analysis and again, a single factor emerged from the analysis that explained $66.7 \%$ of CPS variance. Internal-consistency reliability, estimated with Cronbach's alpha, was also adequate with a coefficient of 0.93 . However, test-retest reliability, which is another way to test instrument reliability, was not performed in this study. In the Swedish study, ${ }^{27}$ researchers used confirmatory factor analysis (CFA) to test the factorial validity of the scale and the results were good because fit indices, which indicate if the factorial structure of the scale fit the data, were adequate. In fact, the comparative fit index and the non-normed fit index were both 0.99 in this study. When these two indices are $\geq 0.95$, the factorial validity is adequate. ${ }^{31}$ In this study, the CPS was also shown to have concurrent validity with the Rewards of Caregiving Scale $(r=0.76$; $p<0.001)$ and the Caregiver Competence Scale $(r=0.34$; $p<0.001$ ). In addition, internal consistency reliability tested with Cronbach's alpha was adequate (0.94), as well as test-retest reliability (0.70) between the baseline and the 6-week follow-up.

Although the CPS has been used to measure caregiver preparedness in stroke caregivers, ${ }^{32}$ its psychometric properties have not been tested in this population. This is an important limitation for the use of the CPS in research and clinical practice because instrument validity and reliability may vary across populations. ${ }^{33}$ So far, the psychometric properties of the CPS have been tested only on caregivers of older adults and caregivers of palliative care patients, but preparedness in these two populations may differ from preparedness in stroke caregivers. This difference may influence the factorial validity and reliability of an instrument that need to be evaluated to understand if the instrument measures the intended variable with an acceptable measurement error. ${ }^{34}$ Therefore, the purpose this study was to evaluate the factorial structure and reliability of the CPS for caregivers of stroke survivors.

\section{Methods}

\section{Design}

We used a cross-sectional design with a 2-week follow-up for test-retest reliability to conduct this study.

\section{Ethical considerations}

The Institutional Review Board at each Hospital where caregivers and stroke survivors were enrolled approved the study. All caregivers and stroke survivors participating in the study provided written informed consent.

\section{Sample and settings}

Using a convenience-sampling strategy, we recruited caregivers 3 months after stroke survivors had been discharged home from a total of 10 rehabilitation hospitals located in the following central and southern cities in Italy: Viterbo, Tivoli, Rome, Grottaferrata, Potenza, Guidonia, Cosenza, Ragusa, Naples, and Taranto. Caregivers were asked to be enrolled in the study if they met the following inclusion criteria: 1 ) being identified as the main informal caregiver by the stroke survivor without receiving any money compensation; and 2) being willing to provide written consent to participate. Caregivers were excluded from enrollment if their stroke patients: 1) had been previously diagnosed with physical/ motor disorders such as amyotrophic lateral sclerosis, multiple sclerosis, or Parkinson's disease; 2) had a cancer or severe organ failure known to be associated with poor quality of life; 3) had aphasia, reduced level of consciousness, or a significant cognitive impairment (not oriented to place and people); 4) were not willing to sign the informed consent form. We chose these criteria to ensure that we specifically tested the psychometric characteristics of the CPS in a more homogeneous stroke-caregiver population, rather than in a more heterogeneous population of caregivers. These criteria have been adopted in prior studies. ${ }^{35-37}$

\section{Measures}

Caregiver Preparedness Scale. ${ }^{25}$ This instrument includes eight items on caregiver preparedness to care for a patient's physical and emotional needs, setting up services, coping with the stress of caregiving, making caregiving activities pleasant for the caregiver and the stroke survivor, responding and managing emergencies, getting help and information from the health care system, and overall preparedness. Examples of the questions on the scale are "How well prepared do you think you are to take care of your family member's physical needs?" and "How well prepared do you think you are to get the help and information you need from the Health Care System?" Each item is rated between 0 (Not at all prepared) to 4 (Very well prepared), and items are summed for a total score that 
can range from 0 to 32, with higher scores indicative of feeling better prepared for the caregiving role.

Before its use in the Italian population, two nurses with expertise in stroke care and fluent in English and Italian translated the CPS from English into Italian. Then, a bilingual English teacher, with expertise in medical translation, back-translated the Italian version into English. The translator was blinded to the original version. The back-translated version of the CPS was checked by the scale developer (Dr. Patricia Archbold) to assess if the original item content was reflected well in the Italian version of the CPS. We then performed minimal modification. The above translation/backtranslation procedure was successfully used in other studies. ${ }^{38,39}$

Caregiver socio-demographic characteristics included gender, age, marital status, education, relationship with the patient, and living condition. We collected these characteristics data using a specific questionnaire developed by the research team. Trained research assistants abstracted stroke-survivor socio-demographic and clinical data from patients' medical records.

\section{Procedures of data collection}

We approached caregivers and stroke survivors for enrollment on the day of patient's discharge from the rehabilitation hospital. After identifying potential participants based on inclusion and exclusion criteria, research assistants met caregivers and stroke survivors and explained the aim of the study and the procedure for data collection. Specifically, research assistants informed caregivers and stroke survivors that after signing the informed-consent form, the same research assistant would collect stroke survivor's clinical data from the medical record and would contact them for the whole data collection at 3 months from the patient's discharge. Research assistants completed data collection at 3 months at the caregiver's house after making an appointment. We decided to administer the research tool at 3 months from patient's discharge to test the CPS in a stroke caregiver population with at least minimal experience in caregiving. Two weeks after data collection at 3 months, all caregivers received a telephone call for the readministration of the CPS for test-retest. A 2-week interval is considered a standard for test-retest reliability in several nursing research textbooks. ${ }^{33,40}$

\section{Data analysis}

We used SPSS 19.0 and Mplus 7.0 to analyze data in this study. For all analyses, $p$ value less than 0.05 was considered statistically significant. We used descriptive statistics to analyze sociodemographic and clinical data (mean, standard deviation, and frequencies) and each item of the CPS (mean, standard deviation, skewness and kurtosis). The factorial structure of the CPS was evaluated by CFA with a maximum likelihood procedure.

To evaluate CFA solutions, we considered the following fit indices: (a) chi square, (b) Comparative Fit Index (CFI), ${ }^{41}$ (c) Tucker and Lewis's Incremental Index (TLI), ${ }^{42}$ (d) Root Mean Square Error of Approximation (RMSEA), ${ }^{43}$ and (d) Standardized Root Mean Square Residual (SRMR). ${ }^{44}$

We tested CPS internal-consistency reliability with item and composite reliability indicators recommended by Fornell and Larker $^{45-47}$ and with traditional indices based on classical test theory, such as Cronbach's alpha, item-total correlation, and Cronbach's alpha if item deleted. We also tested internal-consistency reliability with the factor score determinacy coefficient, ${ }^{48}$ which is an estimate of the internal consistency of a factor solution; it should be equal to or higher than 0.70 as for Cronbach's alpha. ${ }^{48}$ Test-retest reliability was conducted using Intraclass Correlation Coefficient (ICC).

\section{Results}

Sociodemographic characteristics of caregivers and stroke survivors

A total of 170 caregivers and stroke survivors were approached and 156 gave the consent to be enrolled in the study. We believe the sample of 156 adequately satisfies the established criteria for CFA, considering the simplicity and the parsimony of the model we tested. The average age of caregivers was 54 years $(S D=13.2)$ and most were women (64.7\%); $78 \%$ were married and their level of education was equally distributed among participants. The majority (90\%) of caregivers were spouses or adult children, and over half (58\%) lived with stroke survivors (Table 1 ).

On average, stroke survivors were 70 years old $(S D=11.6)$ and men and women were equally distributed in the sample. Most had experienced ischemic stroke. The majority were married and their education level was low (Table 2). Stroke survivors had hypertension (69.2\%), hypercholesterolemia (31.4\%), and diabetes (33.3\%), among the most common comorbid conditions. They also suffered from more than one chronic condition (Table 2).

\section{Item analysis and factorial structure of the Caregiver Preparedness Scale}

Table 3 summarizes descriptive statistics for each item of the CPS. All items were normally distributed and there was no excessive skewness or kurtosis. On average, the total score of the CPS was $15.42(\mathrm{SD}=6.6)$.

We implemented CFA to test a one-factor model, as reported in the literature. ${ }^{25-27}$ The initial model showed an adequate fit to data in all fit indices with the exception of the results from chi-square and RMSEA. Fit indices were listed as follows: $\chi^{2}(20$, $N=156)=58.5, p<0.001$; RMSEA $=0.11$ (90\% CI 0.08-0.14), $p<0.01$; CFI $=0.96$; TLI $=0.95$; and SRMR $=0.033$. Further examination of the Modification Indices revealed that the partial misfit was mainly caused by excessive covariance between Items 1 and 2. These two items refer to self-assessment of caregiver's capability to care for the physical (Item 1) and emotional (Item 2) needs of the patient. Although much variance in these two items was explained by the latent dimension of the CPS (as evidenced by

Table 1

Caregiver socio-demographic characteristics $(N=156)$.

\begin{tabular}{lrr}
\hline Characteristics & $n$ & $\%$ \\
\hline Age (mean, SD) & 53.8 & 13.2 \\
Gender & 55 & \\
Male & 101 & 35.3 \\
Female & & 64.7 \\
Marital status & 122 & 78.2 \\
Married & 4 & 2.6 \\
Widowed & 20 & 12.8 \\
Single & 10 & 6.4 \\
Separate & & \\
Education & 25 & 16.0 \\
Elementary school & 48 & 30.8 \\
Middle school & 20 & 12.8 \\
Professional school & 40 & 25.6 \\
High school & 23 & 14.7 \\
University degree & & \\
Relationship with patient & 74 & 47.4 \\
Son/daughter & 65 & 41.7 \\
Spouse & 6 & 3.8 \\
Brother/sister & 3 & 1.9 \\
Friend & 4 & 2.6 \\
Grandson & 4 & 2.6 \\
Son/daughter in law & 90 & 57.7 \\
Living with patient & & \\
\hline & & \\
\hline & &
\end{tabular}


Table 2

Stroke survivor socio-demographic characteristics and comorbidities $(N=156)$.

\begin{tabular}{|c|c|c|}
\hline Characteristics & $n$ & $\%$ \\
\hline Age (mean, SD) & 69.7 & 11.6 \\
\hline \multicolumn{3}{|l|}{ Gender } \\
\hline Male & 77 & 49.4 \\
\hline Female & 79 & 50.6 \\
\hline \multicolumn{3}{|l|}{ Marital status } \\
\hline Married & 94 & 60.3 \\
\hline Widowed & 45 & 28.8 \\
\hline Single & 12 & 7.7 \\
\hline Separate & 5 & 3.2 \\
\hline \multicolumn{3}{|l|}{ Education } \\
\hline Elementary school & 66 & 42.3 \\
\hline Middle school & 34 & 21.8 \\
\hline Professional school & 10 & 6.4 \\
\hline High school & 35 & 22.4 \\
\hline University degree & 11 & 7.1 \\
\hline \multicolumn{3}{|l|}{ Type of stroke } \\
\hline Ischemic & 124 & 79.5 \\
\hline Hemorrhagic & 26 & 16.7 \\
\hline Micro-infarct & 6 & 3.8 \\
\hline \multicolumn{3}{|l|}{ Stroke side } \\
\hline Right hemisphere & 75 & 48.1 \\
\hline Left hemisphere & 70 & 44.9 \\
\hline Widespread & 11 & 7.1 \\
\hline \multicolumn{3}{|l|}{ Comorbidities } \\
\hline Hypertension & 108 & 69.2 \\
\hline Hypercholesterolemia & 49 & 31.4 \\
\hline Diabetes & 52 & 33.3 \\
\hline Atrial fibrillation & 23 & 14.7 \\
\hline Myocardial infarctions & 15 & 9.6 \\
\hline Periphery vascular disease & 15 & 9.6 \\
\hline Thyroid disease & 15 & 9.6 \\
\hline Congestive heart failure & 13 & 8.3 \\
\hline COPD & 10 & 6.4 \\
\hline Other comorbidities & 11 & 7.1 \\
\hline
\end{tabular}

Patients could suffer more than one condition; COPD = chronic obstructive pulmonary disease.

high loadings of these two items above 0.70), this covariance was thought to be partially due to the specific domain of caring for the needs of stroke survivors. To account for this excess of covariance in the model, we respecified the model by allowing residuals of Items

Table 3

Item descriptive statistics for the CPS.

\begin{tabular}{|c|c|c|c|c|}
\hline & Mean & SD & Skewness & Kurtosis \\
\hline $\begin{array}{l}\text { 1. How well prepared do you think } \\
\text { you are to take care of your } \\
\text { family member's physical needs? }\end{array}$ & 2.01 & 0.940 & 0.065 & -0.319 \\
\hline $\begin{array}{l}\text { 2. How well prepared do you think } \\
\text { you are to take care of his or her } \\
\text { emotional needs? }\end{array}$ & 2.07 & 0.994 & 0.042 & -0.562 \\
\hline $\begin{array}{l}\text { 3. How well prepared do you think } \\
\text { you are to find out about and set } \\
\text { up services for him or her? }\end{array}$ & 1.99 & 0.984 & 0.220 & -0.593 \\
\hline $\begin{array}{l}\text { 4. How well prepared do you think } \\
\text { you are for the stress of caregiving? }\end{array}$ & 1.85 & 0.935 & 0.342 & -0.274 \\
\hline $\begin{array}{l}\text { 5. How well prepared do you think } \\
\text { you are to make caregiving } \\
\text { activities pleasant for both you } \\
\text { and your family member? }\end{array}$ & 1.83 & 1.001 & 0.275 & -0.151 \\
\hline $\begin{array}{l}\text { 6. How well prepared do you think } \\
\text { you are to respond to and handle } \\
\text { emergencies that involve him or her? }\end{array}$ & 1.69 & 1.060 & 0.338 & -0.617 \\
\hline $\begin{array}{l}\text { 7. How well prepared do you think } \\
\text { you are to get the help and } \\
\text { information you need from the } \\
\text { health care system? }\end{array}$ & 1.98 & 0.962 & 0.037 & -0.510 \\
\hline $\begin{array}{l}\text { 8. Overall, how well prepared do you } \\
\text { think you are to care for your } \\
\text { family member? }\end{array}$ & 2.00 & 0.920 & -0.048 & -0.232 \\
\hline
\end{tabular}

1 and 2 to freely correlate. The respecified model fit the data well with the following fit indices: $\chi^{2}(19, N=156)=35.9, p<0.01$; RMSEA $=0.074(90 \%$ CI 0.03-0.11), $p=0.14 ; \mathrm{CFI}=0.98 ; \mathrm{TLI}=0.98$; and SRMR $=0.024$ (Fig. 1). Loadings for the CPS ranged from 0.742 to 0.899 and were statistically significant. Average variance extracted from the CFA was 65\%, which was higher than the level of $50 \%$ recommended by Fornell and Larker. ${ }^{45,46}$

Another criterion that can be used to suggest the presence of a unique dimension is related to the magnitude of the "residual correlation" (i.e., the portion of the correlation among items that is not explained by common factors $)^{47}$; if these residual correlations are lower than $|0.1|$, then the entire substantial correlation among items is explained by the common factors, whereas non-explained variance is marginal. In our case, all residual correlations were lower than $|0.1|$, supporting the conclusion that the one factor model explained the variance shared by the items, and that there was no more common variance to be accounted for beyond what was explained by this single factor. These findings thus support the factorial validity of the CPS.

\section{Reliability analysis}

Each item contributed to the scale fairly well and all coefficients of item reliability index and item total correlation $\left(r_{\mathrm{jx}}\right)$ were higher than the recommended level of 0.30 (Table 4). The composite reliability index was 0.93 and Cronbach's alpha was 0.94. Eliminating any item did not improve the reliability of the scale. The factor score determinacy coefficient was equal to 0.97 , which further supports the high internal consistency of the scale. Testretest reliability at 2 weeks was supported by an ICC of 0.92 (95\% CI 0.89-0.94, $p<0.001$ ).

\section{Discussion}

The aim of this study was to test the psychometric properties of the CPS in caregivers of stroke survivors. The results from our study showed that construct validity and reliability of the CPS were excellent in this population. CFA supported the unidimensionality of the scale found in other caregiver populations. ${ }^{25,27}$ CFA showed that loadings of the latent variable in each item were above the recommended value of 0.30 . These findings indicated that the latent variable has a high impact on items. Although covariance between residuals of Item 1 (measuring preparedness to take care of a patient's physical needs) and Item 2 (measuring preparedness to take care of a patient's emotional needs) was allowed to correlate, this correlation was weaker than the effect of the latent variable on the same items ( 0.38 vs. 0.75 for Item 1 and 0.38 vs. 0.74 for Item 2). As recommended by Fornell ${ }^{49}$ and Bagozzi, ${ }^{50}$ it is reasonable to let residuals correlate with each other when their

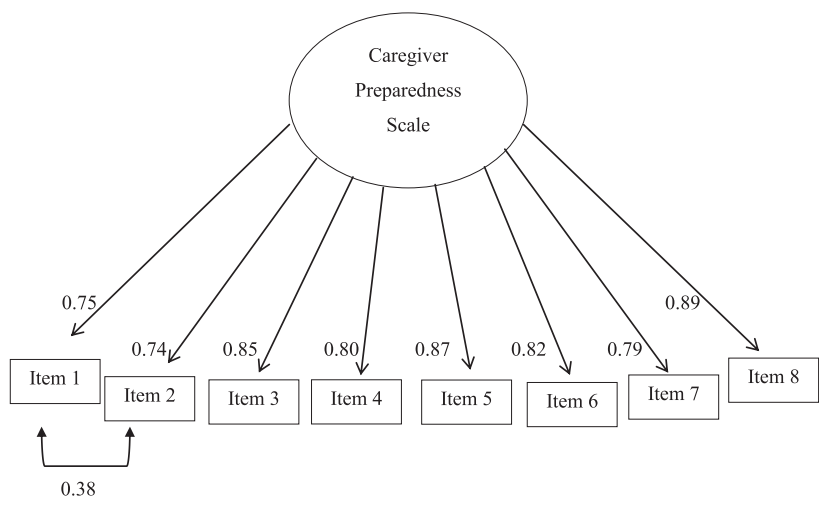

Fig. 1. Confirmative factor analysis of the CPS 
Table 4

Reliability of the CPS.

\begin{tabular}{llll}
\hline & IRI & $r_{\mathrm{jx}}$ & $\alpha-\mathrm{X}$ \\
\hline Item 1 & 0.57 & 0.755 & 0.938 \\
Item 2 & 0.55 & 0.743 & 0.939 \\
Item 3 & 0.72 & 0.832 & 0.932 \\
Item 4 & 0.65 & 0.772 & 0.936 \\
Item 5 & 0.76 & 0.798 & 0.932 \\
Item 6 & 0.69 & 0.749 & 0.935 \\
Item 7 & 0.63 & 0.870 & 0.938 \\
Item 8 & 0.81 & 0.930 \\
\hline
\end{tabular}

IRI $=$ Item Reliability Index; $r_{\mathrm{jx}}=$ Item-total correlation; $\alpha-\mathrm{x}=$ Cronbach's alpha without the item.

specification does not alter the other parameters in the model and there is theoretical or methodological rationale. The strong correlation between Item 1 and Item $2(r=0.73 ; p<0.001)$ may indicate that preparedness to satisfy patient's physical and emotional needs were consistent in this sample; This means that caregivers who perceived higher preparedness to satisfy patient's physical needs also perceived higher preparedness to satisfy emotional needs and vice versa.

We used traditional as well as innovative methods to analyze reliability of the CPS such as the item and composite reliability indicators recommended by Fornell and Larker ${ }^{45-47}$ and the factor score determinacy coefficient. Although traditional Cronbach's alpha is a more commonly used index to assess internal coherence, it has been shown to underestimate true reliability value. ${ }^{51}$ Moreover, Cronbach's alpha does not reflect the scale's factorial structure underlying correlations between items. Item and composite reliability indices have the advantage of giving estimates of reliability coherent with the factor solutions tested with confirmatory and exploratory approaches. Overall, traditional and alternative measures of internal coherence converged to demonstrate a high level of reliability for the 8-item CPS. However, because this study was conducted only in a group of Italian participants, the psychometric properties of the CPS may vary in other populations.

Our findings demonstrated that the CPS has strong psychometric support to measure caregiver preparedness for caregiving of stroke survivors. Using the CPS may help health-care providers identify family members with less caregiver preparedness and assess specific areas where interventions are needed. Additional support for family members with less caregiver preparedness may help family members enhance caregiver preparedness and adjust their caregiver role. Ostwald et al (2009) reported that preparedness for caregiving is a predictor of stress in caregivers of stroke survivors. Better caregiver preparedness in the early period after stroke may reduce caregiver stress and decrease subsequent stressrelated morbidity in this population.

The CPS does not have a specific theoretical underpinning. In fact, when Archbold et $\mathrm{al}^{25}$ developed this scale, their main focus was on caregiver role strain, and caregiver preparedness was considered only an antecedent of responses to family care in a broader theoretical framework based on the role theory. ${ }^{52}$ We were not able to find a specific theory or conceptual framework on preparedness in the literature. Ziemba ${ }^{53}$ attempted to conceptualize caregiver preparedness, hypothesizing that caregiver preparedness was composed of the following dimensions: knowledge, ability, commitment, and affinity for caregiving. However, when computing factor analysis on data from 117 adult daughter caregivers to older parents, Ziemba found that caregiver preparedness was composed of only three dimensions: ability, knowledge, and commitment. Clearly, a conceptualization of caregiver preparedness is scarce in the literature; the dimensions identified by Ziemba $^{53}$ may be a starting point to build a more articulated theoretical framework. Because researchers have shown that caregiver preparedness greatly impacts patient and caregiver outcomes, the development of a theory on preparedness may help in the development of the science in this field.

Limitations of this study include a cross-sectional design, convenience sampling, and a relatively homogeneous sample selection with only Italians. A longitudinal study, with diverse racial/ethnic groups, is required to assess how preparedness of caregiving would change over time. However, because sensitivity to change of the CPS was not tested, this instrument characteristics should be evaluated before drawing conclusion on caregiver preparedness measured over time.

Considering sampling issues, one may question if a sample of 156 participants is sufficient to carry a CFA. Established guidelines ${ }^{54}$ indicate that 5 or 10 to 20 participants per estimated parameter would be sufficient to conduct a CFA. If the variables are highly reliable and correlated, the effects are strong, and the model is not overly complex, smaller samples would be adequate. ${ }^{55,56}$ In other words, CFA models can perform well, even with small samples. ${ }^{57}$ In our study there are a small number of observed variables $(n=8)$, a fairly simple model positing one single factor, a small number of parameters ( 7 factor loadings, 8 residual variances, 1 residual covariance, 1 factor variance), very high correlations among observed variables (ranging from 0.54 to 0.77 , with a mean of 0.68 and a standard deviation of 0.06 ), and reliability estimates far above 0.90 . Thus, we believe that our sample size of 156 participants meets the requirement needed for stable results.

Another limitation is that the CPS was not developed based on a theoretical underpinning for stroke-caregiver preparedness. Thus, our CFA was based on the factorial structure of prior psychometric work performed in other populations. Although prior studies showed that the CPS items reflect stroke-caregiver preparedness, ${ }^{25-27}$ and contrasting group validity of the CPS in this population is supported, ${ }^{58}$ additional studies may be required for further validity testing. Given that some stroke survivors have physical and psychological disability, more dimensions or specific items may be needed to construct a model of preparedness in caregivers of stroke survivors.

Strengths include both traditional and innovative methods used for reliability analysis of the CPS in the study. Moreover, to the best of our knowledge, this is the first study to investigate the psychometric properties of the CPS in caregivers of stroke survivors; thus, we were able to illuminate a previously unexplored area.

\section{Conclusion}

All health care systems confront large economic expenditures and more and more health care for patients is moving toward home care rather than hospital care; thus, informal caregivers play an important role in providing care to patients with complex conditions. ${ }^{59}$ Caregiving, however, can be stressful to family members, especially when they are uncertain about their caregiver role or appropriate support, or information is not provided to them, as has been shown in caregivers of stroke survivors. ${ }^{32,60}$ The CPS has shown excellent validity and reliability in a sample of Italian caregivers of stroke survivors. The CPS is highly recommended for clinicians to assess a new caregiver's perception of how prepared they feel for taking on this important role.

\section{Acknowledgments}

This study was funded by the Center of Excellence for Nursing Scholarship, Rome, Italy.

Dr. Eeeseung Byun is currently supported by a training grant from the National Institutes of Health National Institute of Nursing 
Research (T32NR007088). We thank Dr. Kathryn Lee, Department of Family Health Care Nursing, UCSF School of Nursing, for contributing her time to read and comment on the final draft.

\section{References}

1. World Health Report. Primary Care Now More Than Ever, http://www.who.int/ whr/2008/whr08_en.pdf; 2008. Accessed 14.08.14.

2. Lopez-Hartmann M, Wens J, Verhoeven V, Remmen R. The effect of caregiver support interventions for informal caregivers of community-dwelling frail elderly: a systematic review. Int J Integr Care. 2012;12:e133.

3. National Alliance for Caregiving. Caregiving in the U.S. 2009, http://www. caregiving.org/pdf/research/CaregivingUSAllAgesExecSum.pdf; 2011. Accessed 14.08.14

4. Anderson R, Mikulic B, Vermeylen G, Lyly-Yrjanainen M, Zigante V. Second European Quality of Life Survey - Overview. Dublin: European Foundation for the Improvement of Living and Working Conditions; 2009.

5. Glendinning C, Tjadens F, Arksey H, Moore JM, Moran N, Nies H. Care Provision Within Families and Its Socio-economic Impact on Care Providers. University of New York; 2009.

6. Ministero della Salute. Assistenza domiciliare agli anziani - ADI 2010 e trend 2005-2010, http://www.salute.gov.it/portale/documentazione/p6 2 8 _ 3 _ 1. jsp? lingua $=$ italiano\&id $=5 ; 2012$. Accessed 14.08.14.

7. Schoeni RF, Ofstedal MB. Key themes in research on the demography of aging. Demography. 2010;47(suppl 1):S5-S15.

8. Oliva J, Vilaplana C, Osuna R. [The social value of informal care provided to elderly dependent people in Spain]. Gac Sanit. 2011;25(suppl 2):108-114.

9. Gibson MJ, Houser A. Valuing the Invaluable: A New Look at the Economic Value of Family Caregiving. Issue Brief (Public Policy Institute (American Association of Retired Persons)); 2007:1-12.

10. Schumacher KL, Stewart BJ, Archbold PG, Caparro M, Mutale F, Agrawal S. Effects of caregiving demand, mutuality, and preparedness on family caregiver outcomes during cancer treatment. Oncol Nurs Forum. 2008;35:49-56.

11. Northouse LL, Katapodi MC, Song L, Zhang L, Mood DW. Interventions with family caregivers of cancer patients: meta-analysis of randomized trials. $C A$ Cancer J Clin. 2010;60:317-339.

12. Carter JH, Lyons KS, Stewart BJ, Archbold PG, Scobee R. Does age make a difference in caregiver strain? Comparison of young versus older caregivers in early-stage Parkinson's disease. Mov Disord. 2010;25:724-730.

13. Grant M, Sun V, Fujinami R, et al. Family caregiver burden, skills preparedness, and quality of life in non-small cell lung cancer. Oncol Nurs Forum. 2013;40: 337-346.

14. Schumacher KL, Stewart BJ, Archbold PG. Mutuality and preparedness moderate the effects of caregiving demand on cancer family caregiver outcomes. Nurs Res. 2007:56:425-433.

15. Ahn S, Hochhalter AK, Moudouni DK, Smith ML, Ory MG. Self-reported physical and mental health of older adults: the roles of caregiving and resources. Maturitas. 2012;71:62-69.

16. Henriksson A, Arestedt K. Exploring factors and caregiver outcomes associated with feelings of preparedness for caregiving in family caregivers in palliative care: a correlational, cross-sectional study. Palliat Med. 2013;27:639-646.

17. European Registers of Stroke IHeuschmann PU, Di Carlo A, et al. Incidence of stroke in Europe at the beginning of the 21st century. Stroke. 2009;40:15571563.

18. Zhang Y, Chapman AM, Plested M, Jackson D, Purroy F. The incidence, prevalence, and mortality of stroke in France, Germany, Italy, Spain, the UK, and the US: a literature review. Stroke Res Treat. 2012;2012:436125.

19. Fletcher-Smith JC, Walker MF, Cobley CS, Steultjens EM, Sackley CM. Occupational therapy for care home residents with stroke. Cochrane Database Syst Rev. 2013;6:CD010116.

20. Lutz BJ, Young ME, Cox KJ, Martz C, Creasy KR. The crisis of stroke: experiences of patients and their family caregivers. Top Stroke Rehabil. 2011:18:786-797.

21. Plank A, Mazzoni V, Cavada L. Becoming a caregiver: new family carers' experience during the transition from hospital to home. J Clin Nurs. 2012;21: 2072-2082.

22. Bhattacharjee M, Vairale J, Gawali K, Dalal PM. Factors affecting burden on caregivers of stroke survivors: population-based study in Mumbai (India). Ann Indian Acad Neurol. 2012;15:113-119.

23. Tao H, Ellenbecker $\mathrm{CH}$, Chen J, Zhan L, Dalton J. The influence of social environmental factors on rehospitalization among patients receiving home health care services. ANS Adv Nurs Sci. 2012;35:346-358.

24. Rolley J, Smith J, DiGiacomo M, Salamonson Y, Davidson P. The caregiving role following percutaneous coronary intervention. J Clin Nurs. 2011;20:227-235.

25. Archbold PG, Stewart BJ, Greenlick MR, Harvath T. Mutuality and preparedness as predictors of caregiver role strain. Res Nurs Health. 1990;13:375-384.

26. Hudson PL, Hayman-White K. Measuring the psychosocial characteristics of family caregivers of palliative care patients: psychometric properties of nine self-report instruments. J Pain Symptom Manage. 2006;31:215-228.

27. Henriksson A, Andershed B, Benzein E, Arestedt K. Adaptation and psychometric evaluation of the Preparedness for Caregiving Scale, Caregiver Competence Scale and Rewards of Caregiving Scale in a sample of Swedish family members of patients with life-threatening illness. Palliat Med. 2012;26: 930-938.

28. Henriksson A, Arestedt K, Benzein E, Ternestedt BM, Andershed B. Effects of a support group programme for patients with life-threatening illness during ongoing palliative care. Palliat Med. 2013;27:257-264.

29. Kneeshaw MF, Considine RM, Jennings J. Mutuality and preparedness of family caregivers for elderly women after bypass surgery. Appl Nurs Res. 1999;12: $128-135$.

30. Polit DF, Beck CT. Essentials of Nursing Research. 8th ed. Philadelphia: Lippincott Williams \& Wilkins; 2014.

31. Hu L, Bentler PM. Cutoff criteria for fit indexes in covariance structure analysis: conventional criteria versus new alternatives. Struct Equ Modeling. 1999;6:1-55.

32. Ostwald SK, Bernal MP, Cron SG, Godwin KM. Stress experienced by stroke survivors and spousal caregivers during the first year after discharge from inpatient rehabilitation. Top Stroke Rehabil. 2009;16:93-104.

33. Polit DF, Bech CT. Essentials of Nursing Research: Appraising Evidence for Nursing Practice. Philadelphia: Lippincott Williams \& Wilkins; 2014.

34. Kaplan RM, Saccuzzo DP. Psychological Testing: Principles, Applications, E Issues. 8th ed. Belmont, CA: Wadsworth, Cengage Learning; 2013.

35. Vellone E, Savini S, Barbato N, Carovillano G, Caramia M, Alvaro R. Quality of life in stroke survivors: first results from the reliability and validity of the Italian version of the Stroke Impact Scale 3.0. Ann Ig. 2010;22:469-479.

36. Vellone E, Savini S, Simeone S, et al. [Reliability of caregivers in assessing the quality of life of stroke survivors: an explorative study]. Assist Inferm Ric 2011;30:180-188.

37. Simeone S, Savini S, Cohen MZ, Alvaro R, Vellone E. The experience of stroke survivors three months after being discharged home: a phenomenological investigation. Eur J Cardiovasc Nurs; 2014;. http://dx.doi.org/10.1177/147451 5114522886 [epub 2014 Feb 2].

38. Vellone E, Riegel B, Cocchieri A, et al. Psychometric properties of the self-care of heart failure index version 6.2. Res Nurs Health. 2013;36:500-511.

39. Vellone E, Savini S, Fida R, et al. Psychometric evaluation of the stroke impact scale 3.0. J Cardiovasc Nurs; 2014; http://dx.doi.org/10.1097/JCN.00000000 00000145 [epub 2014 Apr 1].

40. Polit FP, Bech CT. Nursing Research: Principles and Methods. Philadelphia: Lippincott Williams \& Wilkins; 2004

41. Bentler PM. Comparative fit indexes in structural models. Psychol Bull. 1990;107:238-246.

42. Tucker LR, Lewis C. A reliability coefficient for maximum likelihood factor analysis. Psychometrika. 1973:38:1-10.

43. Steiger JH. Structural model evaluation and modification: an interval estimation approach. Multivar Behav Res. 1990;25:173-180.

44. Joreskog KG, Sorbom D. Lisrel 8: Structural Equation Modeling With the Simplis Command Language. Uppsala University. Sweden: Psychology Press; 1993.

45. Fornell C, Larcker DF. Evaluating structural equation models with unobservable variables and measurement error. J Mark Res. 1981;18:39-51.

46. Bagozzi RP. Principles of Marketing Research. Cambridge, MA: Blackwell Business; 1994.

47. Bagozzi RP, Yi Y. Specification, evaluation, and interpretation of structural equation models. I Acad Mark Sci. 2012;40:26.

48. Tabachnick BG, Fidell LS. Using Multivariate Statistics. 3rd ed. New York, NY: HarperCollins College Publishers; 1996.

49. Fornell C. Issues in the application of covariance structure analysis: a comment J Consum Res. 1983;9:443-448.

50. Bagozzi RP. Issues in the application of covariance structure analysis: a further comment. J Consum Res. 1983:9:449-450.

51. Raykov T. Scale construction and development using structural equation modeling. In: Hoyle RH, ed. Handbook of Structural Equation Modeling. New York: The Guilford Press; 2012:472-492.

52. Burr WR, Leigh GK, Day RD, Constantine J. Symbolic interaction and the family. In: Burr WR, Hill R, Nye F, Reiss IL, eds. Contemporary theories about the family, vol. 2. New York: The Free Press; 1979:42-111.

53. Ziemba RA. Factors Influencing the Preparedness of Adult Daughters for Taking Care of Elderly Parents. Doctoral Dissertation. Ann Arbor, MI: University of Michigan; 2002.

54. Kline RB. Principles and Practice of Structural Equation Modeling. 3rd ed. New York: Guilford Press; 2011.

55. Bearden WO, Sharma S, Teel JE. Sample size effects on chi square and other statistics used in evaluating causal models. J Mark Res. 1982;19:425-430.

56. Bollen KA. Overall fit in covariance structure models: two types of sample size effects. Psychol Bull. 1990;107:256-259.

57. Geweke JF, Singleton KJ. Maximum likelihood "confirmatory" factor analysis of economic time series. Int Econ Rev. 1981:22:37-54.

58. Shyu YI, Chen MC, Chen ST, Wang HP, Shao JH. A family caregiver-oriented discharge planning program for older stroke patients and their family caregivers. J Clin Nurs. 2008:17:2497-2508.

59. Mendoza H, Martin MJ, Garcia A, et al. 'Hospital at home' care model as an effective alternative in the management of decompensated chronic heart failure. Eur J Heart Fail. 2009;11:1208-1213.

60. Etters L, Goodall D, Harrison BE. Caregiver burden among dementia patient caregivers: a review of the literature. J Am Acad Nurse Pract. 2008;20: 423-428. 